\section{Riscos e benefícios do rastreamento do câncer de mama no Brasil}

\author{
Risks and benefits of breast cancer screening \\ in Brazil
}

Arn Migowski ${ }^{1}$

${ }^{1}$ Divisão de Detecção Precoce e Apoio à Organização de Rede, Coordenação Geral de Prevenção e Vigilância, Instituto Nacional de Câncer (INCA). arnmigowski@yahoo.com.br

Ao longo de cinco décadas um forte consenso foi construído em torno do rastreamento mamográfico, baseado, em grande parte, na crença de que este não está associado a riscos e que apresenta benefício de grande magnitude na incidência, sobrevida e mortalidade por câncer de mama.

O artigo de Rodrigues et al. ${ }^{1}$ apresenta análises interessantes sobre fatores associados à realização de rastreamento do câncer de mama no Brasil. Ao longo de todo o artigo os autores caracterizam o rastreamento com mamografia como prevenção do câncer de mama. Por fim, os autores concluem que a promoção da saúde através da prevenção do câncer de mama contribui para a diminuição da incidência desta doença. No entanto, o rastreamento deste câncer não é capaz de prevenir a doença e, portanto, não reduz a incidência do câncer de mama. Ao contrário, o rastreamento mamográfico aumenta em muito a incidência deste câncer, principalmente em função do sobrediagnóstico ${ }^{2,3}$.

Já Soares et al. ${ }^{4}$ afirmam em sua carta que os avanços no tratamento deste câncer não reduziram o impacto do rastreamento na evolução favorável das curvas de sobrevida nos estudos nacionais. Os autores baseiam essa afirmação na diferença de sobrevida entre os diversos estádios da doença. Contudo, eles partem da premissa de que o rastreamento mamográfico é sempre o responsável por toda a diferença de distribuição de estádios apresentada pelas pacientes, quando na realidade, $o$ estádio ao diagnóstico depende de diversas outras variáveis, tais como o comportamento biológico do tumor e o acesso ao serviço de saúde de casos sintomáticos. Soma-se a isso o fato de que o rastreamento mamográfico tem impacto desprezível na redução do estádio IV, justamente o com pior prognóstico ${ }^{2}$. Por outro lado, o rastreamento aumenta os casos em estádio inicial, a maioria dos quais representa apenas sobrediagnótico ${ }^{2,3}$.

A carta contrapõe os resultados de sobrediagnóstico demonstrados no ensaio de Miller, com a redução da mortalidade apresentada pelo estudo pan-canadense ${ }^{4}$. Todavia, enquanto o primeiro é um ensaio clínico randomizado ${ }^{3}$, considerado entre os três melhores estudos já feitos sobre o tema pela Colaboração Cochrane, o pan-canadense é um estudo observacional, que apresenta diversos problemas, como ausência de alocação aleatória da intervenção e possível inclusão de casos prevalentes no grupo controle.

Os autores da carta afirmam ainda que a dificuldade de acesso aos serviços de saúde no Brasil representa um fator limitante para a aplicação dos resultados do ensaio canadense no país. Todavia, como o rastreamento em si não resolve problemas de acesso à confirmação diagnóstica $\mathrm{e}$ ao tratamento, esses problemas quando existentes tenderiam a diminuir o efeito dessa intervenção na mortalidade e não aumentá-lo. Adicionalmente, a prevalência do câncer de mama no Brasil é geralmente menor quando comparada aos países onde os ensaios clínicos foram realizados, o que aumenta o número de falso-positivos e diminui o benefício real do rastreamento.

A garantia de que o rastreamento mamográfico traga mais benefícios do que danos para a população brasileira passa tanto pela resolução dos problemas da sua qualidade, apontados na carta de Soares, quanto pela adequação da sua curta periodicidade, conforme apontado no estudo de Rodrigues et al. ${ }^{1}$.

\section{Referências}

1. Rodrigues JD, Cruz MS, Paixão NA. Uma análise da prevenção do câncer de mama no Brasil. Cien Saude Colet 2015; 20(10):3163-3176.

2. Bleyer A, Welch G. Effect of Three Decades of Screening Mammography on Breast-Cancer Incidence. $N$ Engl J Med 2012; 367(21):1998-2005.

3. Miller AB, Wall C, Baines CJ, Sun P, To T, Narod SA. Twenty five year follow-up for breast cancer incidence and mortality of the Canadian National Breast Screening Study: randomised screening trial. BMJ 2014; 348:g366.

4. Soares LR, Freitas-Junior R, Oliveira JC. A detecção precoce do câncer de mama e o impacto do rastreamento mamográfico nas taxas de sobrevida. Cien Saude Colet 2015; 20(10):3285-3286. 


\section{Os autores respondem à carta}

Mércia Santos da Cruz ${ }^{1}$

Adriano Nascimento da Paixão ${ }^{1}$

Juliana Dantas Rodrigues ${ }^{1}$

${ }^{1}$ Departamento de Economia, Centro de Ciências Sociais Aplicadas, Universidade Federal da Paraíba da Paraíba.

Comumente, quando o indivíduo efetiva ações para melhorar a sua saúde, mesmo não possuindo sintomas de nenhuma doença, o mesmo incorre na prevenção primária (forma de prevenção que inibe por completo o risco da aquisição de determinada doença - por exemplo, o ato de vacinar-se). Por outro lado, a busca por exames preventivos e de diagnóstico precoce para algumas patologias, como o câncer, também se constitui como uma forma de prevenção, dado que neste caso o diagnóstico precoce visa aumentar as chances de vida ou sobrevida do doente e reduzir os efeitos perversos da doença. Neste caso, a realização de exames mamográficos constitui-se como medida preventiva contra o câncer de mama, especificamente, realizar exames para checar a ocorrência de doenças define-se como prevenção secundária. 